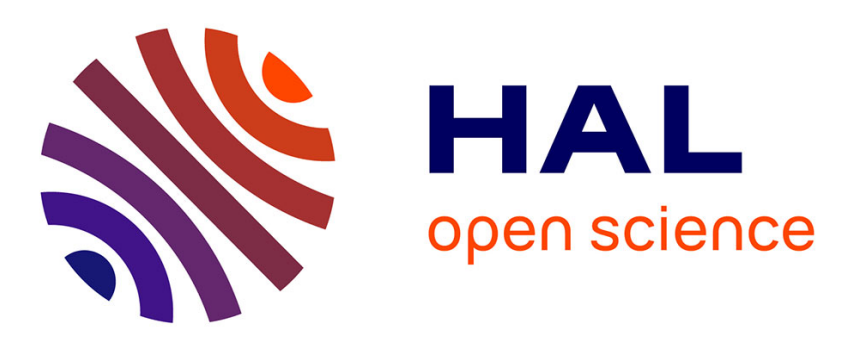

\title{
Independently Tuning Elastomer Softness and Firmness by Incorporating Side Chain Mixtures into Bottlebrush Network Strands
}

\author{
Andrew Keith, Charles Clair, Abdelaziz Lallam, Egor Bersenev, Dimitri \\ Ivanov, Yuan Tian, Andrey Dobrynin, Sergei Sheiko
}

\section{To cite this version:}

Andrew Keith, Charles Clair, Abdelaziz Lallam, Egor Bersenev, Dimitri Ivanov, et al.. Independently Tuning Elastomer Softness and Firmness by Incorporating Side Chain Mixtures into Bottlebrush Network Strands. Macromolecules, 2020, 53 (21), pp.9306-9312. 10.1021/acs.macromol.0c01725 . hal-03095867

\section{HAL Id: hal-03095867 https://hal.science/hal-03095867}

Submitted on 7 Jan 2021

HAL is a multi-disciplinary open access archive for the deposit and dissemination of scientific research documents, whether they are published or not. The documents may come from teaching and research institutions in France or abroad, or from public or private research centers.
L'archive ouverte pluridisciplinaire HAL, est destinée au dépôt et à la diffusion de documents scientifiques de niveau recherche, publiés ou non, émanant des établissements d'enseignement et de recherche français ou étrangers, des laboratoires publics ou privés. 


\section{Independently tuning elastomer softness and}

\section{firmness by incorporating side chain mixtures into}

\section{bottlebrush network strands}

Andrew N. Keith, ${ }^{1}$ Charles Clair, ${ }^{2}$ Abdelaziz Lallam, ${ }^{2}$ Egor A. Bersenev,${ }^{4,5}$ Dimitri A. Ivanov, ${ }^{3,45}$ Yuan Tian, ${ }^{1}$ Andrey V. Dobrynin, ${ }^{l}$ Sergei S. Sheiko ${ }^{1 *}$

${ }^{1}$ Department of Chemistry, University of North Carolina at Chapel Hill, 27599, USA

${ }^{2}$ Université de Haute Alsace, Laboratoire de Physique et Mécanique Textiles, 11 rue Alfred Werner, F-68093 Mulhouse Cedex, France

${ }^{3}$ Institut de Sciences des Matériaux de Mulhouse-IS2M, CNRS UMR 7361, 15, rue Jean Starcky, F-68057 Mulhouse, France

${ }^{4}$ Lomonosov Moscow State University, Leninskie Gory 1, 119991, Moscow, Russian Federation

${ }^{5}$ Institute of Problems of Chemical Physics, Russian Academy of Sciences, Chernogolovka, Moscow region, 142432, Russian Federation 
For Table of Contents Use Only

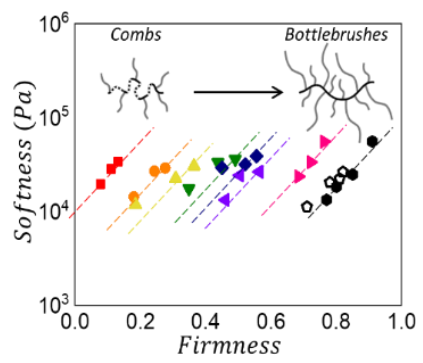

ABSTRACT

Softness and firmness are opposing traits that synergistically define the elastic response of biological systems. Currently, no single class of synthetic materials including elastomers and gels provides independent control of these mechanical characteristics, particularly without altering chemical composition. To address this challenge, we explore a hierarchical bottom-up approach via architectural modulation of bottlebrush mesoblocks followed by their self-assembly into linearbrush-linear triblock copolymer networks. By judiciously incorporating side chains of different lengths, we seamlessly demonstrate full control over elastomer firmness at a fixed Young's modulus thus bypassing the infinitely laborious synthesis of targeted side chain lengths. This industrially scalable iteration upon the design-by-architecture approach to network construction delivers thermoplastic elastomers with unprecedented softness-firmness combinations desired in soft robotics, flexible electronics, and biomedical devices.

\section{INTRODUCTION}

Stress-strain responses of elastic materials can be expressed by two distinct mechanical characteristics: (i) Young's modulus $\left(E_{0}\right)$, which defines material stiffness (or softness) at small strains, and (ii) firmness $(\beta)$ which characterizes stiffening during deformation (Figure 1A). ${ }^{1,2}$ 
Although firmness is colloquially used in the English language as a synonym of stiffness, various sectors in industry use this mechanical label to characterize the resistance to deformation of soft systems such as mattresses, ${ }^{3}$ food, ${ }^{4}$ and biological tissues. ${ }^{5}$ In other words, firmness is not stiffness. This distinction is observable in stress-strain curves of representative classes of soft materials (Figure 1A). Specifically, tissues and gels may show similar softness with $E_{0} \sim 10 \mathrm{kPa}$, but their stress-strain curves rapidly diverge during deformation. ${ }^{6}$ This intense strain-stiffening represents one of Nature's defense mechanisms preventing accidental rupture and uncontrolled sagging of living tissues.

While the molecular mechanism of biological firmness is complex and viscoelastic in nature, ${ }^{7,8}$ the structural interpretation of polymer network's elastic response is straight forward. ${ }^{1,9}$ The nonlinear modulus increase results from finite extensibility of network strands defined by the initial mean-square end-to-end distance between crosslinks $\left\langle R_{i n}^{2}\right\rangle$ to the square of the strand contour length $R_{\max }^{2}$ as $\beta=\left\langle R_{\text {in }}^{2}\right\rangle / R_{\text {max }}^{2}$ within interval $0<\beta<1$ (Figure 1A). Networks with flexible strands $\left(R_{\text {in }} \ll R_{\max }\right)$ display weak strain-stiffening with $\beta \cong 0.01-0.1$, while semiflexible networks $\left(R_{\text {in }} \sim R_{\max }\right)$ are characterized by $\beta \approx 0.1-1$.

For various elastic systems, the softness $\left(E_{0}\right)$ and firmness $(\beta)$ are readily quantified by fitting experimental stress-strain curves (Figure 1A) with the following equation of state: ${ }^{9}$

$$
\sigma_{\text {true }}(\lambda)=\frac{E}{9}\left(\lambda^{2}-\lambda^{-1}\right)\left[1+2\left(1-\frac{\beta\left(\lambda^{2}+2 \lambda^{-1}\right)}{3}\right)^{-2}\right]
$$

where $E$ is the structural modulus related to crosslink density. Jointly, $E$ and $\beta$ define the Young's modulus $E_{0}=E\left(1+2(1-\beta)^{-2}\right) / 3$, which corresponds to the stress-strain slope at $\lambda \rightarrow 0$. By plotting the extracted parameters of various elastic systems on an $\left[E_{0}, \beta\right]$ map, we expose a remarkable absence of independent control over $E_{0}$ and $\beta$ to cover the entire map (Figure 1B). 
For instance, conventional elastomers with flexible strands exhibit low firmness $\beta<0.01$ and relatively high modulus $E_{0}>10^{5} \mathrm{~Pa}$ as they are architecturally limited by chain entanglements. ${ }^{10,11}$ In polymer gels, swelling with solvent enables decoupling the elastic features that leads to both dilution of network crosslinks and strand extension towards lower $E_{0}$ and higher $\beta$, respectively. However, gels are also limited by strand entanglements bounding firmness to $\beta<0.2$ (Figure 1B) ${ }^{6,11}$ Although significant progress has been achieved with more complex architectures such as dual network gels ${ }^{12}$ and sacrificial crosslinks, ${ }^{13}$ these systems face similar limitations $(\beta<0.4)$ and typically possess high $E_{0}$ due to dense crosslinking. ${ }^{6}$ On the opposite end of the $\left[E_{0}, \beta\right]$ map, we realize biology's unrivaled mechanics demonstrating broad softness $10^{2}<$ $E_{0}<10^{6}$ and firmness $\beta>0.7$ (Figure 1B). ${ }^{6,14-16}$ Yet, from the $\left[E_{0}, \beta\right]$ map, it is apparent that neither Nature nor current synthetic strategies contain the tools to successfully decouple $E_{0}, \beta$ over the entire elastic landscape. Therefore, the goal of this study is to develop a materials design platform that broadly and independently varies firmness and softness. Specifically, we aim to demonstrate continuous firmness enhancement from $\beta \sim 0 \rightarrow 1$ at constant Young's modulus $E_{0}$.
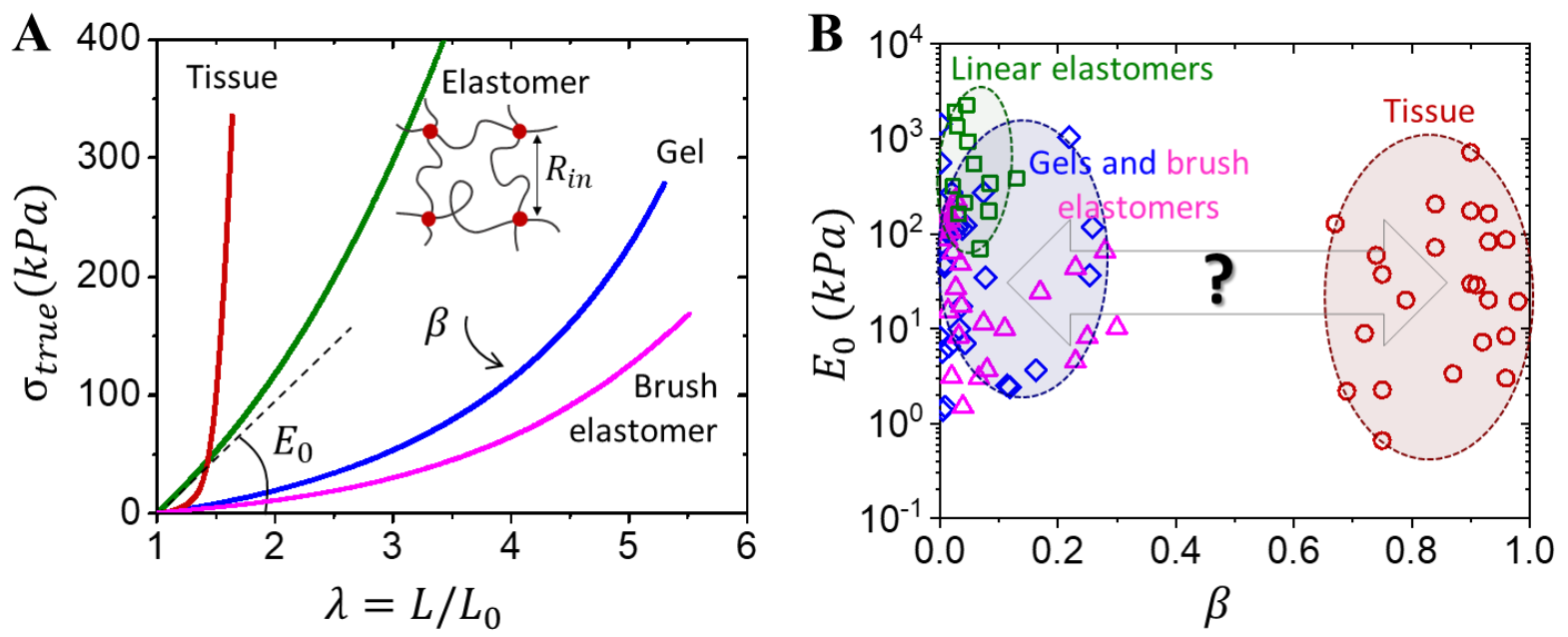

Figure 1. The elastic landscape. (A) Representative stress-elongation curves of various elastic materials with similar softness $\left(E_{0}=20 \mathrm{kPa}\right)$, but vastly distinct firmness: PAM gel (blue) ${ }^{6}{ }^{\mathrm{a}}$ 
covalently crosslinked brush elastomer (magenta, $n_{x}=600, n_{s c}=14, n_{g}=2$ ), ${ }^{17}$ and fetal membrane tissue (red). ${ }^{6}$ Linear elastomers (green) cannot reach tissue relevant softness due to linear entanglements. ${ }^{10}(\mathrm{~B})\left[E_{0}, \beta\right]$ map depicting distinct classes of materials including linear elastomers $(\square),{ }^{1,10,11}$ gels $(\diamond),{ }^{6}$ brush-like elastomers $(\triangle),{ }^{17,18}$ and tissue $(O) .{ }^{6}$

In this regard, brush-like polymers ${ }^{6,17-27}$ offer a promising path forward by exploiting the oxymoronic duality of side chains as mechanical softeners and stiffeners. At a given network strand length, introducing side chains has two concurrent effects: (i) increased strand volume resulting in decreased $E_{0}$ and (ii) strand extension resulting in enhanced $\beta$. Two classes of brush elastomers mimic the mechanical properties of gels and tissues: (i) covalently crosslinked elastomers $^{17,18}$ and (ii) physically crosslinked plastomers obtained by self-assembly of linearbrush-linear (LBL) triblock copolymers. ${ }^{6,27}$ The elastic footprint of covalently crosslinked brushlike elastomers is strikingly similar to those of gels with limited firmness of $\beta<0.3$ (Figure 1B). ${ }^{17,18}$ Therefore, we focus on plastomers, which afford higher firmness due to the strong segregation of both the compositionally and architecturally distinct blocks. ${ }^{6,27,28}$ In previous studies, varying brush block length and linear block length led to an undesirable simultaneous increase of $E_{0}$ and $\beta \cdot{ }^{27}$ To enable independent control over $E_{0}$ and $\beta$, we employed longer side chains, which excel at respectively augmenting strand volume and stiffness. ${ }^{6}$ Although these materials successfully decouple $E_{0}$ and $\beta$ as the first elastomers to replicate the unprecedented softness-firmness combination of tissue, they encompassed a narrow elastic range. Therefore, broadly augmenting both side chain length and linear block volume fraction paves a pathway to covering the entire landscape within a single copolymer platform as investigated by this report.

\section{RESULTS AND DISCUSSION}


One of the most efficient ways to vary the average degree of polymerization (DP) of side chains, $\left\langle n_{s c}\right\rangle$, is through copolymerization of small and large (macro)monomers at controlled molar fractions (Figure 2). This side chain mixing approach bypasses the commercial limitations found in previous brush systems with monodisperse side chains ${ }^{6,27}$ by enabling broad and continuous tuning of $\left\langle n_{s c}\right\rangle$ with minimum synthetic efforts while delivering elastomers with well-defined mechanical properties.
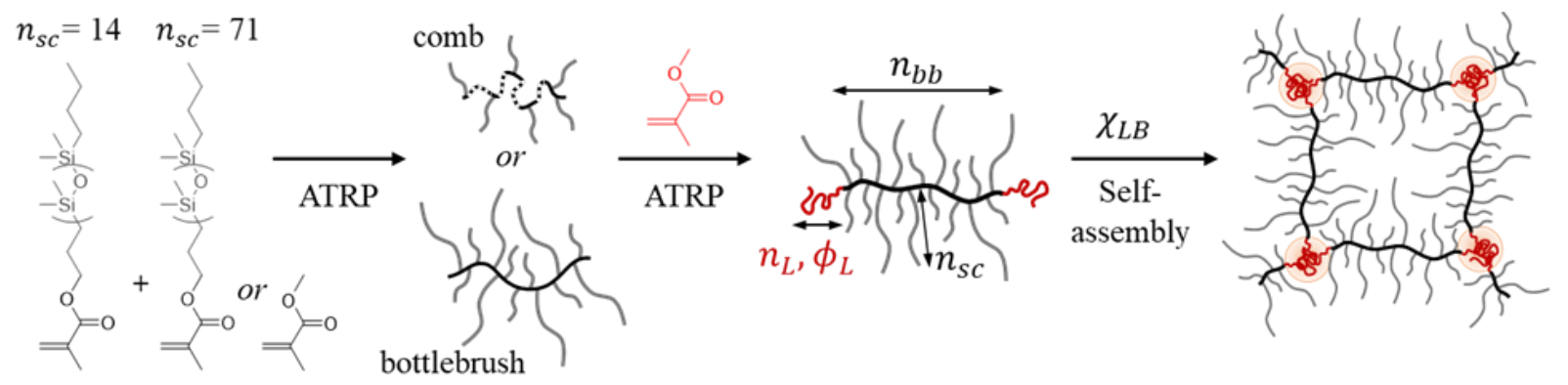

Figure 2. Linear-Bottlebrush-Linear (LBL) plastomer synthetic route. Copolymerization of two PDMS-MA macromonomers with $n_{s c}=14$ and 71, and MMA monomer enables accurately tuning the average $\left\langle n_{s c}\right\rangle$ of the brush block within LBL macromolecules that subsequently self-assemble into physical networks.

To validate this approach, we have synthesized nine series of LBL triblock copolymers with increasing $\left\langle n_{s c}\right\rangle$ (Table 1) via atom transfer radical polymerization (ATRP). In the comb group (Series 1-3), $\left\langle n_{s c}\right\rangle$ was controlled by the copolymerization of poly(dimethylsiloxane)-methacrylate (PDMS-MA) macromonomer $\left(n_{s c}=14\right)$ and methyl methacrylate (MMA) monomer (Figure 2). In the bottlebrush group (Series 4-9), $\left\langle n_{s c}\right\rangle$ was varied by randomly copolymerizing (PDMS-MA) macromonomers with $n_{s c}=14$ and 71 (Figure 2). Each series contains triblocks with different volume fractions $\left(\phi_{L}\right)$ of PMMA chosen as the linear block (for complete data sets see Table S1, Table S2 and Figure S1-S18), although additional L-block chemistry should be investigated in future work. Side chain inclusion during polymerization was monitored by time resolved ${ }^{1} \mathrm{H}-\mathrm{NMR}$ showing an anticipated enrichment of shorter macromonomers at initial degrees of conversion 
$(\sim 10 \%)$ but yield brush blocks within stoichiometric expectations $(<15 \%)$ (Figure S1-S10, Table S3 and Table S4). The resulting bottlebrush dimensions and side-chain homogeneity along the backbone were verified by atomic force microscopy (AFM) and ultra-small angle X-ray (USAXS) (Figure 3). Molecular imaging of dense monolayers by AFM reveals evenly spaced worm-like macromolecules with no signs of bimodality (Figure 3A). The spacing increases linearly with side chain weight average $\left\langle n_{s c, w}\right\rangle$ (Figure 3B), which is consistent with the thermodynamically preferred adsorption of longer side chains to substrates. ${ }^{29}$ Likewise, USAXS measurements of bulk LBL plastomers and B block melts show a consistent monomodal shift of a characteristic scattering peak around $q \approx 1 \mathrm{~nm}^{-1}$ (Figure $3 \mathrm{C}$ ), which is typically oversimplified as a backbone-backbone correlation or brush diameter. ${ }^{28,30-32}$ The resulting spacing $\xi=2 \pi / q$ scales with $\left\langle n_{s c}\right\rangle$ as $\xi \sim\left\langle n_{s c}\right\rangle^{0.41 \pm 0.01}$ (Figure 3D) and is consistent with recent small-angle neutron scattering $\left(\xi \sim n_{s c}^{0.40 \pm 0.04}\right),{ }^{32}$ computer simulations $\left(\xi \sim n_{s c}^{0.39 \pm 0.01}\right)$, and theoretical studies $\left(\xi \sim n_{s c}^{3 / 8}\right) .{ }^{33}$ The last highlights the complex physical origin of $\xi$ due to coupled density fluctuations from both backbone monomers and side chains constrained by melt incompressibility. ${ }^{33}$ The theory considers dependence of $n_{s c}$ on the effective bottlebrush block Kuhn length as $b_{K} \sim n_{s c}^{1 / 2}$ resulting in $\xi \sim n_{s c}^{1 / 4} b_{K}^{1 / 4} \sim n_{s c}^{3 / 8}$, which is weaker than the distance between brush backbones $\xi \sim n_{s c}^{1 / 2}$. A weaker power law may be also explained by an increased distance between neighboring side chains along the backbone with longer $n_{s c}$ as $l \sim n_{s c}^{\alpha}$, which would lead to $\xi \sim n_{s c}^{1 / 2} / l=n_{s c}^{1 / 2-\alpha}$. 
Table 1: Molecular parameters of LBL block-copolymers

\begin{tabular}{|c|c|c|c|c|c|c|}
\hline Sample & $m_{1} / m_{2}^{c}$ & $n_{s c}{ }^{d}$ & $n_{b b}{ }^{e}$ & $n_{L}^{f}$ & $\phi_{L}{ }^{g}$ & Schematics \\
\hline \multirow{3}{*}{$\begin{array}{c}\text { Series } 1^{a} \\
\text { MMA/M11 50/50 }\end{array}$} & \multirow{3}{*}{$52 / 48$} & 7.5 & 336 & 78 & 0.069 & \\
\hline & & 7.5 & 336 & 102 & 0.089 & \\
\hline & & 7.5 & 336 & 119 & 0.102 & \\
\hline \multirow{3}{*}{$\begin{array}{c}\text { Series } 2^{a} \\
\text { MMA/M11 25/75 }\end{array}$} & \multirow{3}{*}{$27 / 73$} & 10.8 & 196 & 34 & 0.038 & \\
\hline & & 10.8 & 196 & 58 & 0.062 & \\
\hline & & 10.8 & 196 & 64 & 0.068 & \\
\hline \multirow{3}{*}{$\begin{array}{c}\text { Series } 3^{a} \\
\text { MMA/M11 10/90 }\end{array}$} & \multirow{3}{*}{$11 / 89$} & 12.9 & 197 & 29 & 0.027 & \\
\hline & & 12.9 & 197 & 52 & 0.047 & \\
\hline & & 12.9 & 197 & 76 & 0.067 & \\
\hline \multirow{3}{*}{$\begin{array}{c}\text { Series } 4^{b} \\
\text { M11/M17 100/0 }\end{array}$} & \multirow{3}{*}{$100 / 0$} & 14.4 & 363 & 57 & 0.026 & \\
\hline & & 14.4 & 363 & 116 & 0.053 & \\
\hline & & 14.4 & 363 & 168 & 0.077 & \\
\hline \multirow{3}{*}{$\begin{array}{c}\text { Series } 5^{b} \\
\text { M11/M17 75/25 }\end{array}$} & \multirow{3}{*}{$84 / 16$} & 23.6 & 285 & 88 & 0.026 & \\
\hline & & 23.6 & 285 & 123 & 0.036 & \\
\hline & & 23.6 & 285 & 201 & 0.059 & \\
\hline \multirow{3}{*}{$\begin{array}{c}\text { Series } 6^{b} \\
\text { M11/M17 50/50 }\end{array}$} & \multirow{3}{*}{$66 / 34$} & 33.8 & 249 & 62 & 0.014 & \\
\hline & & 33.8 & 249 & 106 & 0.024 & \\
\hline & & 33.8 & 249 & 133 & 0.029 & \\
\hline \multirow{3}{*}{$\begin{array}{c}\text { Series } 7^{b} \\
\text { M11/M17 25/75 }\end{array}$} & \multirow{3}{*}{$42 / 58$} & 47.1 & 308 & 187 & 0.025 & \\
\hline & & 47.1 & 308 & 261 & 0.035 & \\
\hline & & 47.1 & 308 & 430 & 0.058 & \\
\hline \multirow{4}{*}{$\begin{array}{c}\text { Series } 8^{b} \\
\text { M11/M17 0/100 }\end{array}$} & \multirow{4}{*}{$0 / 100$} & 71.2 & 447 & 288 & 0.020 & Bottlehrushes \\
\hline & & 71.2 & 447 & 604 & 0.041 & \\
\hline & & 71.2 & 447 & 772 & 0.052 & \\
\hline & & 71.2 & 447 & 894 & 0.060 & \\
\hline \multirow{4}{*}{$\begin{array}{c}\text { Series } 9^{b} \\
\text { M11/M17 0/100 }\end{array}$} & \multirow{4}{*}{$0 / 100$} & 71.2 & 292 & 144 & 0.021 & \\
\hline & & 71.2 & 292 & 263 & 0.038 & \\
\hline & & 71.2 & 292 & 468 & 0.067 & \\
\hline & & 71.2 & 292 & 696 & 0.099 & \\
\hline
\end{tabular}

${ }^{a}$ Brush blocks copolymerized with molar fractions MMA and PDMS-MA $n_{s c}=14$ (M11) macromonomers. ${ }^{b}$ Brush blocks copolymerized with molar fractions of PDMS-MA $n_{s c}=14$ (M11) and $n_{s c}=71$ (M17) macromonomers. ${ }^{c}$ Final copolymer molar fractions measured by ${ }^{1} \mathrm{H}-$ NMR (Figure S1-S10) where $m_{1}$ and $m_{2}$ are molar fractions of the respective (macro)monomers. ${ }^{d}$ Number average degree polymerization of side chains calculated as $n_{s c}=m_{1} n_{s c, 1}+m_{2} n_{s c, 2}$. ${ }^{e}$ Number average degree polymerization of brush backbones. ${ }^{f, g}$ Degree polymerization and volume fraction of linear MMA blocks as determined from ${ }^{1} \mathrm{H}-\mathrm{NMR}$ (Figure S11-S18) where $\rho_{P M M A}=$ $1.15 \mathrm{~g} / \mathrm{mL}, \rho_{P D M S}=0.96 \mathrm{~g} / \mathrm{mL}$. 

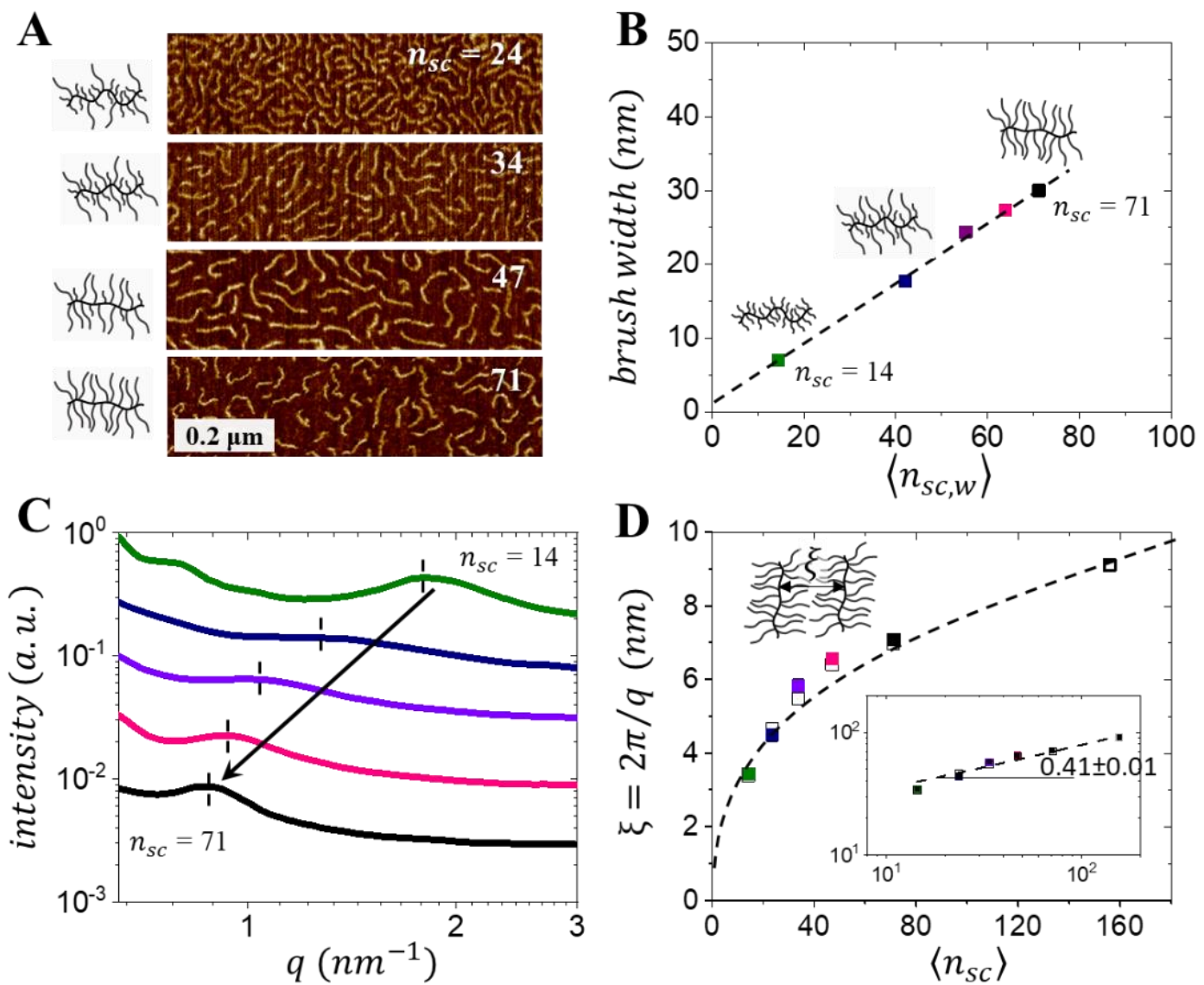

Figure 3. LBL Characterization. (A) Atomic force microscopy micrographs of Langmuir-Blodget monolayers of brush blocks show increased interbrush distance with increasing fractions of long side chains $\left(n_{s c}=71\right)$. (B) Interbrush distance as determined by AFM (Figure S19 and Table S5) increases linearly with weight average $\left\langle n_{s c, w}\right\rangle$. (C) The brush scattering peak, as determined in recent literature, ${ }^{6,28}$ consistently shifts to lower magnitudes of the scattering wavevector $q$ with increasing number average side chain length $\left\langle n_{s c}\right\rangle$. (D) The brush scattering distance peak position $(\xi=2 \pi / q)$ increases with $\left\langle n_{s c}\right\rangle$ as $\xi \sim\left\langle n_{s c}\right\rangle^{0.41}$ (inset), which is consistent with theoretically predicted scaling behavior $\xi \sim n_{s c}^{3 / 8} \cdot{ }^{25}$ The dashed line corresponds to a linear fit with $\xi=0.5+$ $1.2 n_{s c}^{0.41}$. The solid and open symbols correspond to LBL elastomers and melts of brush blocks, respectively, including a melt of PDMS bottlebrushes with long side chains $\left(n_{s c}=156\right)$ Importantly, upon background subtraction the brush scattering peak reveals its second order which indicates that packing of the bottlebrush segments is characterized by long-range order (cf. Figures S24-25). 
For each sample in all nine series, we measured their stress-elongation response (Figure S20) and characterized their $E_{0}$ and $\beta$ (Figure S20, Table S1 and Table S2). Two sets of representative curves with either similar $E_{0}$ and varied $\beta$ (Figure 4A) or vice versa (Figure 4B) demonstrate the unprecedented ability of the LBL plastomer platform to cover the $\left[E_{0}, \beta\right]$ landscape. In Figure 4A, the curves show significant variation of strain-stiffening $(\beta)$ at nearly constant slope at $\lambda \rightarrow 1\left(E_{0}\right)$ with larger $\left\langle n_{s c}\right\rangle$. In Figure 4B, increasing $E_{0}$ at nearly constant $\beta$ was achieved by concomitantly varying $\left\langle n_{s c}\right\rangle$ and volume fraction of the linear block $\left(\phi_{L}\right)$ as indicated. The corresponding $E_{0}$ and $\beta$ values were extracted by fitting the stress-strain curves with Equation 1 with an $\left[E_{0}, \beta\right]$ map of all synthesized materials confirming near complete $\beta$ coverage within a given $E_{0}$ range (Figure 4C). The map yields several notable correlations highlighted by dashed cross-sectional lines: (i) Horizontal cross section I represent collections of plastomers with constant $E_{0}$ and increasing $\beta$ similar to those found in Figure 4A as achieved by larger $\left\langle n_{s c}\right\rangle$. (ii) Two vertical cross sections II and III correspond to plastomers with constant $\beta$ and variable $E_{0}$ realized by concomitantly varying $\phi_{L}$ and $\left\langle n_{s c}\right\rangle$ (Figure 4B). (iii) Diagonal dashed lines correspond to plastomers with a given $\left\langle n_{s c}\right\rangle$ (Series 1-9 in Table 1), where increasing $\phi_{L}$ simultaneously increases $E_{0}$ and $\beta$ up the coalesced line, which can be exploited to fill the elastic landscape beyond the reported samples. These correlations enable general design rules towards architecturally traversing the $\left[E_{0}, \beta\right]$ landscape. Further theoretical analysis discussed in literature ${ }^{6,34}$ allows collapsing the individual series trends into distinct correlations for bottlebrushes and combs (Figure 4D), which demonstrates overarching universality by normalizing the attained mechanical properties $\left(E_{0}, \beta\right)$ by their corresponding architectural parameters $\left(n_{b b}, n_{s c}, n_{L}, \phi_{L}\right)$. However, trendline boundaries are currently ill-defined as there could be a change in microdomain symmetry upon reaching high $\phi_{L},{ }^{35}$ which will be a topic of future study. 
Further demonstrating the adaptability of the side chain mixing approach, we deliberately introduce heterogeneous distribution of side chains with different $n_{s c}$ along the brush backbone. To this end, we have synthesized two pentablock copolymers $\mathrm{LB}_{14} \mathrm{~B}_{71} \mathrm{~B}_{14} \mathrm{~L}$ and $\mathrm{LB}_{71} \mathrm{~B}_{14} \mathrm{~B}_{71} \mathrm{~L}$, where $\mathrm{B}_{14}$ and $\mathrm{B}_{71}$ correspond of monodisperse blocks with $n_{s c}=14$ or $n_{s c}=71$ side chains, respectively (Figure S21 and Figure S22). The two brush triblocks $\left(\mathrm{B}_{14} \mathrm{~B}_{71} \mathrm{~B}_{14}\right.$ and $\left.\mathrm{B}_{71} \mathrm{~B}_{14} \mathrm{~B}_{71}\right)$ with inverted side chains distributions were grown to have similar $\left\langle n_{s c}\right\rangle \cong 47$ (Table S6), which is analogous to Series 7 in Table 1. The stress-elongation curves (Figure 4E) of these blocky plastomers show slightly lower $\beta$ from Series 7 obtained with random copolymerization (Figure 4F), and although they differ in $\phi_{L}$ and $n_{b b}$ (Table S6), their similar $\left\langle n_{s c}\right\rangle$ enables their selfconsistent trend line that is reminiscent of random copolymerization. This observation suggests that LBL plastomer footprint on the $\left[E_{0}, \beta\right]$ landscape is largely $\left\langle n_{s c}\right\rangle$ controlled, however, the precise effect of side chain distribution within a given brush strand will be investigated in future studies. 
A

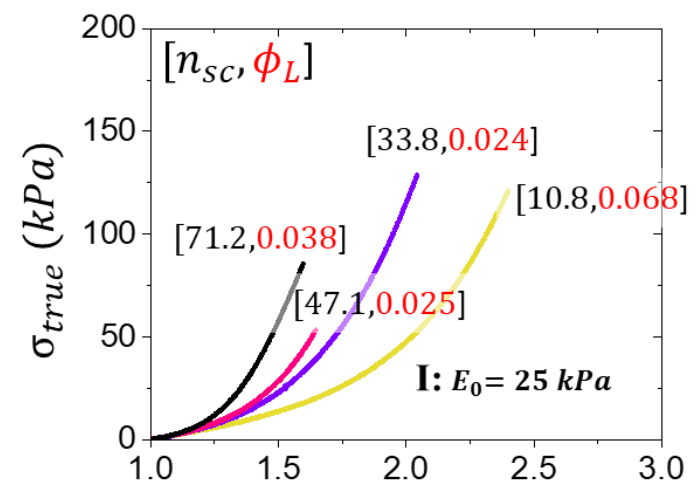

C
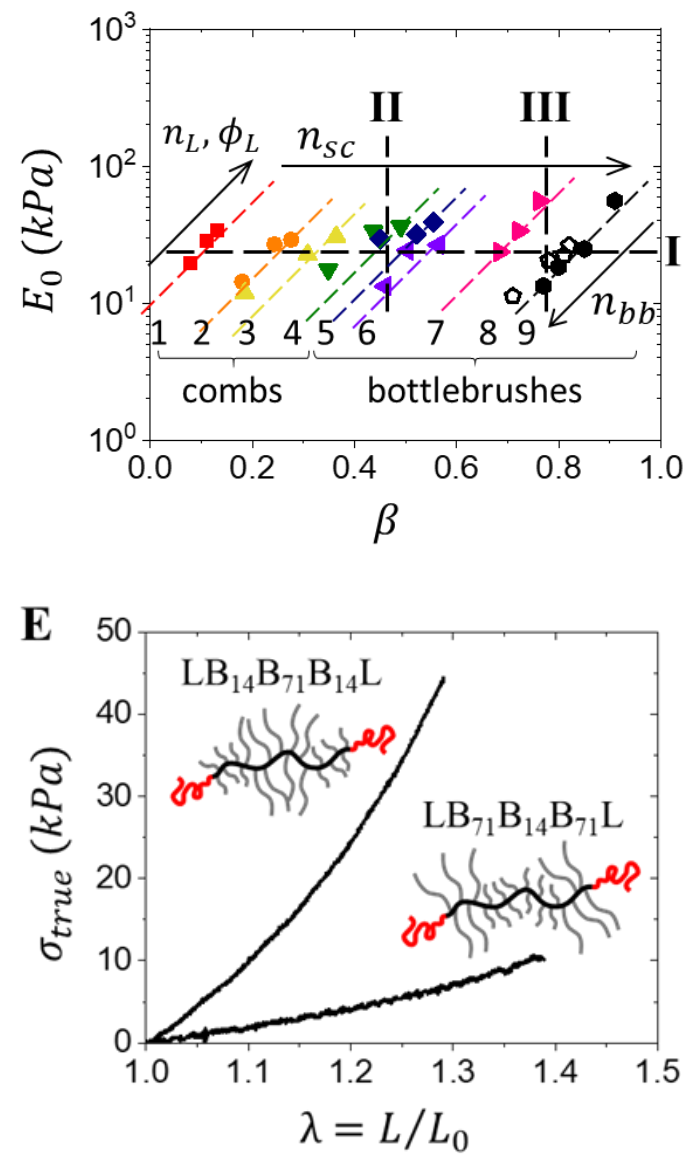

B
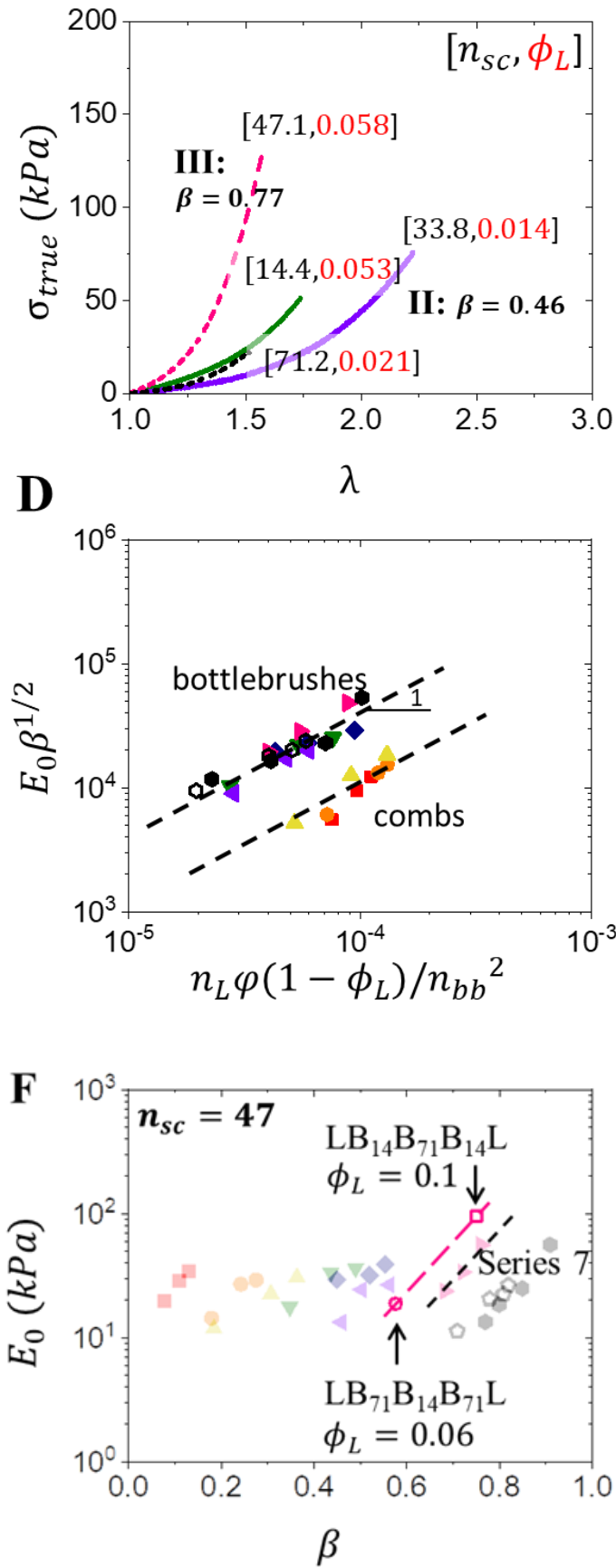

Figure 4. Mechanical Characterization. (A) Stress-elongation curves of selected LBL plastomers with similar $E_{0}=25 \mathrm{kPa}$ and different $\beta$. (B) Stress-elongation curves of LBL plastomers of two groups (dashed vs solid line) respectively with similar $\beta=0.77$ and $\beta=0.46$ but different $E_{0}$. (C) Elastic parameters of reported LBL plastomers extracted from a collection of stress-elongation curves (Figure S20) on an $\left[E_{0}, \beta\right]$ map. Each colored symbol set represents a series according to Table 1. Dashed lines are provided to guide the reader and delineate the coalescence of each series. 
Collections of stress-elongation with either constant $E_{0}$ and different $\beta$ (Figure 4A) or constant $\beta$ and different $E_{0}$ (Figure 4B) may be identified by respectively dropping lateral lines (I) or vertical lines (II,III). General design rules (arrows) can be inferred for tuning mechanical properties $\left(E_{0}\right.$, $\beta)$ with architectural parameters $\left(n_{b b}, n_{s c}, n_{L}, \phi_{L}\right)$. (D) Universal collapse of mechanical properties in relation to their architectural parameters informed by theoretical considerations from literature $^{6,34}$ provides a direct route for programmable design, where $\varphi=n_{g} /\left(n_{g}+n_{s c}\right)=$ $\left(1+n_{s c}\right)^{-1}$ or the volume fraction of the backbone in the brush $\left(n_{g}=1\right)$ block. Both bottlebrushes and combs exhibit distinct coalescence due to their fundamental difference in their effective Kuhn length. ${ }^{36}$ (E) Stress-elongation curve profiles of $\mathrm{LB}_{14} \mathrm{~B}_{71} \mathrm{~B}_{14} \mathrm{~L}$ and $\mathrm{LB}_{71} \mathrm{~B}_{14} \mathrm{~B}_{71} \mathrm{~L}$ pentablock plastomers. (F) $\mathrm{LB}_{14} \mathrm{~B}_{71} \mathrm{~B}_{14} \mathrm{~L}$ and $\mathrm{LB}_{71} \mathrm{~B}_{14} \mathrm{~B}_{71} \mathrm{~L}$ pentablock plastomers on the elastic map programmed with $\left\langle n_{s c}\right\rangle$ similar to series 7 . The observed shift is likely due to small errors in determining $\left\langle n_{s c}\right\rangle$ of randomly mixed brushes (Figure S6 and Figure S7).

\section{CONCLUSION}

In conclusion, self-assembly of linear-bottlebrush-linear macromolecules yields physical networks that are able to span the entire elastic landscape via their architectural multiplet $\left[n_{b b}, n_{s c 1}, n_{s c 2}, n_{L}, \phi_{L}, m_{1}\right]$, where $m_{1}$ is the molar fraction of side chain with DP $=n_{s c 1}$. Specifically, the side chain mixing approach allows covering the entire firmness range at a given Young's modulus to replicate the elastic properties of both synthetic gels and biological tissue.

Thus, the average side chain length $\left\langle n_{s c}\right\rangle$ is the defining architectural feature that enables encoding unique pairings of both softness and firmness into elastomers. We believe this industrially friendly platform that has eluded the polymer field will revolutionize future applications in the emerging biomedical and soft-robotics fields, which to date have been hampered by the lack of access to these materials.

\section{ASSOCIATED CONTENT}


The Supporting Information is available free of charge on the ACS Publications website at DOI:

Synthetic procedures with ${ }^{1} \mathrm{H}-\mathrm{NMR}$ and sample summaries, atomic force microscopy and mechanical characterization with stress-elongation curves of triblock and pentablock plastomers with mixed side chains.

\section{AUTHOR INFORMATION}

\section{Corresponding Author}

Correspondence and requests for materials should be addressed to S.S.S and AVD. E-mails: sergei@email.unc.edu and adobrynin@uakron.edu

\section{Author Contributions}

A.N.K. designed, synthesized, and characterized the monomers, block-copolymers, and polymer networks; A.N.K. performed mechanical tests and AFM experiments. Y.T. and A.V.D. provided theoretical analysis of mechanical properties, developed theoretical foundation for materials design and LBL networks; C.C., A.L., E.B. and D.A.I. conducted X-ray studies and data analysis; S.S.S. is the principal investigator and corresponding author; A.N.K. and S.S.S were primary writers of the manuscript. All authors discussed the results and provided feedback on the manuscript. 


\section{ACKNOWLEDGMENT}

We acknowledge funding from the National Science Foundation (DMR 1921835, DMR 1921923, and DMR 2004048). D.A.I. and E.B. acknowledge the Ministry of Science and Higher Education of Russian Federation for financial support in the frame of project RFME-19X0100, N 075-15-2019-1889 from December 5, 2019. The work was done in the frame of state task № 00742019-0014 (registration № AAAA-A19-119101590029-0). The authors acknowledge perfect technical support of the personnel of the ID02 beamline of the European Synchrotron Radiation Facility (ESRF) in Grenoble, France.

\section{REFERENCES}

(1) Dobrynin, A. V.; Carrillo, J. Y. Universality in Nonlinear Elasticity of Biological and Polymeric Networks and Gels. Macromolecules 2011, 44, 140-146.

(2) Carrillo, J. Y.; MacKintosh, F. C.; Dobyrnin, A. V. Nonlinear Elasticity: from Single Chain to Networks and Gels. Macromolecules 2013, 46, 3679-3692.

(3) Kraft, E. Varying firmness mattress. U.S. Patent 513674 0A, 1996.

(4) Juarez, B.; King. J. J.; Bachlava, E.; Wentzell, A. M.; Mills, J. M. Methods and Compositions for Watermelon Firmness. U.S. Patent 10036032 B2, 2012.

(5) Brown, T.; Brown, S.; Murphy, T. Breast Durometer (mammometer): A Novel Device for Measuring Soft-Tissue Firmness and its Application in Cosmetic Breast Surgery. Aesthetic. Plast. Surg. 2017, 41, 265-274. 
(6) Keith, A. N.; Vatankhah-Varnosfaderani, M.; Clair, C.; Fahimipour, F.; Dashtimoghadam, E.; Lallam, A.; Sztucki, M.; Ivanov, D. A.; Liang, H.; Dobrynin, A. V.; Sheiko, S. S. Bottlebrush Bridge between Soft Gels and Firm Tissues. ACS Cent. Sci. 2020, 6, 413-419.

(7) Blair, G. W. S. A New Criterion for Expressing the 'Intensity of Firmness' of Soft Bodies. Nature 1943, 152, 412.

(8) Faber, T. J.; Jaishankar, A.; McKinley, G. H. Describing the Firmness, Springiness and Rubberiness of Food Gels Using Fractional Calculus. Part I: Theoretical framework. Food Colloids 2017, 62, 311-324.

(9) Sheiko, S.S.; Dobrynin, A.V. Architectural Code for Rubber Elasticity: from Super-Soft to Super-Firm Materials. Macromolecules 2019, 52, 7531-7546.

(10) Daniel. W. F. M.; Burdyńska, J.; Vatankhah-Varnosfaderani, M.; Matyjaszewski, K.; Paturej, J.; Rubinstein, M.; Dobrynin, A. V.; Sheiko, S. S. Solvent-Free, Supersoft and Superelastic Bottlebrush Melts and Networks. Nat. Mater. 2016, 15, 183.

(11) Jacobs, M.; Liang, H.; Dashtimoghadam, E.; Morgan, B. J.; Sheiko, S. S.; Dobrynin, A. V. Nonlinear Elasticity and Swelling of Comb and Bottlebrush Networks. Macromolecules 2019, 52, $5095-5101$.

(12) Gong, J. P.; Katsuyama, Y.; Kurokawa, T.; Osada, Y. Double-Network Hydrogels with Extremely High Mechanical Strength. Adv. Mater. 2003, 15, 1155-1158.

(13) Durcot, E.; Chen, Y.; Bulters, M.; Sijbesma, R. P.; Creton, C. Toughening Elastomers with Sacrificial Bonds and Watching them Break. Science 2014, 344, 186-189. 
(14) Storm, C.; Pastore, J. J.; MacKintosh, F. C.; Lubensky, T. C.; Janmey, P. A. Nonlinear Elasticity in Biological Gels. Nature 2005, 435, 191-194.

(15) Fung, Y. C. Biomechanics: Mechanical Properties of Living Tissues. Springer 1993.

(16) Holzapfel, G. A.; Biomechanics of soft tissue. In Handbook of Material Behavior Models; J. Lemaitre, Ed.; Academic press 2001, pp. 1057-1071.

(17) Vatankhah-Varnoosfaderani, M.; Daniel, W. F. M.; Everhart, M. H.; Pandya, A. A.; Liang, H.; Matyjaszewski, K.; Dobrynin, A. V.; Sheiko, S. S. Mimicking Biological Stress-Strain Behavior with Synthetic Elastomers. Nature 2017, 549, 497-501.

(18) Vatankhah-Varnosfaderani, M.; Daniel, W. F. M.; Zhushma, A. P.; Li, Q.; Morgan, B. J.; Matyjaszewski, K.; Armstrong, D. P.; Spontak, R. J.; Dobrynin, A. V.; Sheiko, S. S. Bottlebrush Elastomers: A New Platform for Freestanding Electroactuation. Adv. Mater. 2017, 29, 1604209.

(19) Pakula, T.; Zhang, Y.; Matyjaszewski, K.; Lee, H.-i.; Boerner, H.; Qin, S.; Berry, G. C. Molecular brushes as super-soft elastomers. Polymer, 2006, 47, 7198-7206.

(20) Sheiko, S. S.; Sumerlin, B. S.; Matyjaszewski, K. Cylindrical Molecular Brushes: Synthesis, Characterization, and Properties. Prog. Polym. Sci. 2008, 33, 759-785.

(21) Verduzco, R.; Li, X.; Pesek, S. L.; Stein, G. E. Structure, Function, Self-Assembly, and Applications of Bottlebrush Copolymers. Chem. Soc. Rev. 2015, 44, 2405-2420.

(22) Reynolds, V. G.; Mukherjee, S.; Xie, R.; Levi, A. E.; Atassi, A.; Uchiyama, T.; Wang, H.; Chabinyc, M. L.; Bates, C. M. Super-Soft Solvent-Free Bottlebrush Elastomers for Touch Sensing. Mater. Horiz. 2020, 7, 181-187. 
(23) Sarapas, J. M.; Chan, E. P.; Rettner, E. M.; Beers, K. L. Compressing and Swelling to Study the Structure of Extremely Soft Bottlebrush Networks Prepared by ROMP. Macromolecules 2018, $51,2359-2366$.

(24) Liberman-Martin, A. L.; Chu, C. K.; Grubbs, R. H. Application of Bottlebrush Block Copolymers as Photonic Crystals. Macromol. Rapid Commun. 2017, 38, 1700058/1-15.

(25) Bolton, J.; Rzayev, J. Synthesis and Melt Self-Assembly of PS-PMMA-PLA Triblock Bottlebrush Copolymers. Macromolecules 2014, 47, 2864-2874.

(26) Dalsin, S. J.; Rions-Maehren, T. G.; Beam, M. D.; Bates, F. S.; Hillmyer, M. A.; Matsen, M. W. Bottlebrush Block Polymers: Quantitative Theory and Experiments. ACS Nano 2015, 9, 12233-12245.

(27) Vatankhah-Varnosfaderani, M.; Keith, A. N.; Cong, Y.; Liang, H.; Rosenthal, M.; Sztucki, M.; Clair, C.; Magonov, S.; Ivanov, D. A.; Dobrynin, A. V.; Sheiko, S. S. Chameleon-like Elastomers with Molecularly Encoded Strain-Adaptive Stiffening and Coloration. Science 2018, $359,1509-1513$.

(28) Clair C.; Lallam, A.; Rosenthal, M.; Sztucki, M.; Vatankhah-Varnosfaderani, M.; Keith, A. N.; Cong, Y.; Liang, H.; Dobrynin, A. V.; Sheiko, S. S.; Ivanov, D. A. Strained Bottlebrushes in Super-Soft Physical Networks. ACS Macro. Lett. 2019, 8, 530-534.

(29) Burdynska, J.; Daniel, W.; Li, Y.; Robertson, B.; Sheiko, S. S.; Matyjaszewski, K. Molecular Bottlebrushes with Bimodal Length Distribution of Side Chains. Macromolecules 2015, $48,4813-4822$. 
(30) Pakula, T.; Minkin, P.; L. Beers, K.; Matyjaszewski, K. Structure and Dynamics in Melts of Bottle-Brush Polymers. Polymeric Materials: Science \& Engineering 2001, 84, 1006-1007.

(31) López-Barrón, C. R.; Tsou, A. H.; Younker, J. M.; Norman, A. I.; Schaefer, J. J.; Hagadorn, J. R.; Throckmorton, J. A. Microstructure of Crystallizable $\alpha$-Olefin Molecular Bottlebrushes: Isotactic and Atactic Poly(1-octadecene). Macromolecules 2018, 51, 872-883.

(32) Sarapas, J. M.; Martin, T. B.; Chremos, A.; Douglas, J. F.; Beers, K. L. Bottlebrush Polymers in the Melt and Polyelectrolytes in Solution Share Common Structural Features. PNAS 2020, $117,5168-5175$.

(33) Liang, H.; Wang, Z.; Dobrynin, A.V. Scattering from Melts of Combs and Bottlebrushes: Molecular Dynamics Simulations and Theoretical Study. Macromolecules 2019, 52, 5555-5562.

(34) Liang, H.; Wang, Z.; Dobrynin, A. V. Strain-Adaptive Self-Assembled Networks of LinearBottlebrush-Linear Copolymers. Macromolecules 2019, 52, 8617-8624.

(35) Zhulina, E. B.; Sheiko, S. S.; Dobrynin, A.V.; Borisov O.V. Microphase Segregation in the Melts of Bottlebrush Block Copolymers. Macromolecules 2020, 53, 2582-2593.

(36) Liang, H.; Morgan, B. J.; Xie, G.; Martinez, M.; Zhulina, E. B.; Matyjaszewski, K.; Sheiko, S. S.; Dobrynin, A. V. Universality of the Entanglement Plateau Modulus of Comb and Bottlebrush Polymer Melts. Macromolecules 2018, 51, 10028-10039. 